\title{
Stroke and neck bruit in a boy with Crohn's disease
}

Ryosaku Tomiyama ${ }^{1,2}$, Akira Hokama ${ }^{3}$, Erika Koga ${ }^{3}$, Kohei Shimabukuro $^{3}$, Yuiko Oishi ${ }^{3}$, Tetsuya Ohira ${ }^{3}$, Atsushi Iraha ${ }^{1}$, Tetsu Kinjo ${ }^{3}$, Jiro Fujita ${ }^{1}$

${ }^{1}$ Department of Infectious, Respiratory, and Digestive Medicine, Graduate School of Medicine, University of the Ryukyus, Nishihara, ${ }^{2}$ Department of Gastroenterology, Naha City Hospital, Naha; ${ }^{3}$ Department of Endoscopy, Graduate School of Medicine, University of the Ryukyus, Nishihara, Japan

Question: A 15-year-old boy with CD presented with acute onset of headache, vomiting, and systemic convulsion lasting several minutes. On the diagnosis at 9-year-old, CD location was ileocolonic, and behavior was non-stricturing, non-penetrating with pediatric CDAI (PCDAI) value of 57.5. His medication included prednisolone $(2.5 \mathrm{mg} /$ day $)$ and sulfasalazine (3 g/day). Physical examination revealed stable vital signs and bruit on the right neck. His blood pressure was 140/106 mmHg in the left arm, whereas 120/104 mmHg on the right side. Paralysis and neurological deficit were not noted. Complete blood cell counts showed white blood cells of $9,900 / \mathrm{mm}^{3}$, hemoglobin of $9.2 \mathrm{~g} / \mathrm{dL}$, and platelets of $375,000 / \mathrm{mm}^{3}$. Biochemical tests showed elevated levels of CRP $(4.48 \mathrm{mg} / \mathrm{dL}$ [reference range, $<0.14 \mathrm{mg} / \mathrm{dL}])$, ESR $(90 \mathrm{~mm} / \mathrm{hr}[2-10 \mathrm{~mm} / \mathrm{hr}])$, $\operatorname{IgG}(3,141 \mathrm{mg} / \mathrm{dL}$ [861-1,747 mg/dL]), IgA (1,714 mg/dL [93$393 \mathrm{mg} / \mathrm{dL}])$, and antinuclear antibody $(\times 320[<\times 20])$. Tests for anti-DNA antibody, antineutrophil cytoplasmic antibody, and lupus anticoagulant were negative. PCDAI value was 37.5. Brain MRI and MR angiography (MRA) were performed (Fig. A and B). What is the most likely diagnosis?

Received February 26, 2019. Revised March 5, 2019.

Accepted March 25, 2019.

Correspondence to Akira Hokama, Department of Endoscopy, Graduate

School of Medicine, University of the Ryukyus, 207 Uehara, Nishihara,

Okinawa 903-0215, Japan. Tel: +81-98-895-1144, Fax: +81-98-895-1414,

E-mail: hokama-a@med.u-ryukyu.ac.jp

\section{Answer to the Images: CD Complicated by Takayasu Arteritis}

Brain MRI showed multiple increased signals in T2 images and fluid attenuated inversion recovery sequences, suggesting cerebral ischemia (Fig. A). MRA showed the occlusion of the left common carotid artery at the origin (arrow) and stenosis of the right subclavian artery (arrow head). Compensatory prominent left carotid artery (asterisk) and collaterals feeding thin external and internal carotid arteries were also presented (Fig. B). Ischemic stroke caused by intracranial arteritis due to Takayasu arteritis (TA) type I (involvement confined to aortic arch branches) was diagnosed. Treatment with $30 \mathrm{mg} /$ day of prednisolone and $200 \mathrm{mg} /$ day of ticlopidine were initiated and symptoms improved. He has been asymptomatic with $10 \mathrm{mg} /$ day of prednisolone for 23 years. Follow-up ileocolonoscopy showed the longitudinal ulcer scar in the descending colon.
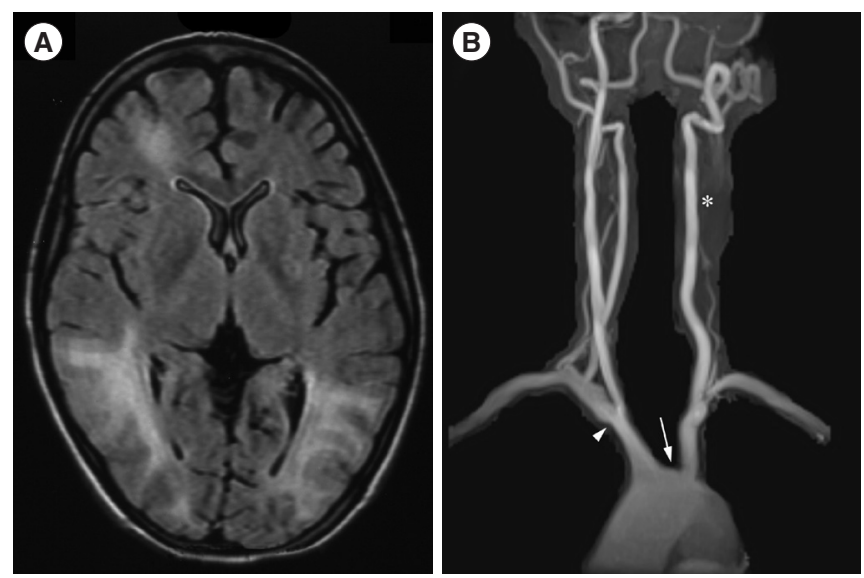
TA is a rare idiopathic, inflammatory and granulomatous vasculitis affecting large arteries, including the aorta and its major branches. ${ }^{1} \mathrm{CD}$ is a chronic IBD with extraintestinal manifestations. Co-existence of TA and CD has been extremely rare and was reported only in nearly 70 cases. $^{2-4}$ The mechanism of this association has not been yet elucidated; however, genetic susceptibilities, such as certain human leucocyte antigens have been suggested to be the shared pathogenesis. ${ }^{1}$ In most co-existence cases, the diagnosis of $\mathrm{CD}$ precedes that of $\mathrm{TA}^{2}$ as in this case. In addition, co-existence patients were younger at the time of diagnosis of TA than those without $\mathrm{CD} .{ }^{4}$ A study indicated that the activities of co-existence occurred in parallel in $43 \% .{ }^{3}$ We should consider the complication of TA when cardiovascular symptoms, such as hypertension or bruits appear in patients with CD. On the contrary, CD should be kept in mind when TA cases are in refractory condition.

\section{FINANCIAL SUPPORT}

The authors received no financial support for the research, authorship, and/or publication of this article.

\section{CONFLICT OF INTEREST}

No potential conflict of interest relevant to this article was reported.

\section{AUTHOR CONTRIBUTION}

Collecting materials, drafting the manuscript: Tomiyama R. Collecting materials: Koga E, Shimabukuro K, Oishi Y, Ohira T, Iraha A, Kinjo T. Reviewing the manuscript: Hokama A. Supervising the study: Fujita J. All authors reviewed the final version of the manuscript.

\section{ORCID}

Hokama A

https://orcid.org/0000-0002-8310-9989

\section{REFERENCES}

1. Tombetti E, Mason JC. Takayasu arteritis: advanced understanding is leading to new horizons. Rheumatology (Oxford) 2019;58:206-219.

2. Kusunoki R, Ishihara S, Sato M, et al. Rare case of Takayasu's arteritis associated with Crohn's disease. Intern Med 2011;50: 1581-1585.

3. Kilic L, Kalyoncu U, Karadag O, et al. Inflammatory bowel diseases and Takayasu's arteritis: coincidence or association? Int J Rheum Dis 2016;19:814-818.

4. Sy A, Khalidi N, Dehghan N, et al. Vasculitis in patients with inflammatory bowel diseases: a study of 32 patients and systematic review of the literature. Semin Arthritis Rheum 2016; 45:475-482. 